\title{
A Preliminary Study on Lung Cancer Prevalence Among Patients with Tuberculosis in Lesotho
}

\author{
Mopa Alina Sooro*, Thibello Malikelle, Refiloe Leteka, Lejeremane Kobo, \\ Maseabata Ramathebane \\ Department of Pharmacy, Pharmacology, Faculty of Health Sciences, National University of Lesotho, Lesotho, Roma
}

\section{Email address:}

ma.sooro@nul.ls (M. A. Sooro), matobatsisesoane@gmail.com (M. A. Sooro)

${ }^{*}$ Corresponding author

\section{To cite this article:}

Mopa Alina Sooro, Thibello Malikelle, Refiloe Leteka, Lejeremane Kobo, Maseabata Ramathebane. A Preliminary Study on Lung Cancer Prevalence Among Patients with Tuberculosis in Lesotho. Cancer Research Journal. Vol. 9, No. 3, 2021, pp. 148-153.

doi: $10.11648 /$ j.crj.20210903.13

Received: June 18, 2021; Accepted: June 29, 2021; Published: July 13, 2021

\begin{abstract}
Tuberculosis (TB) is one of the major causes of ill health associated with infection in approximately a quarter of the global population. Lesotho has been ranked among the top 30 high TB burden countries; however the prevalence of lung cancer in Lesotho has been ranked fifth among the top 5 cancers in men. This seemingly lower prevalence of lung cancer could be masked by the fact that there are a number of cancer cases among TB patients that remain undiagnosed. Therefore, a cross-sectional study was done at the $3 \mathrm{~TB}$ centers in Lesotho to investigate the prevalence of lung cancer among patients with TB. This study was done over a 2 months period in April and May 2019. TB patients undergoing treatment at Queen Elizabeth II hospital, St. Joseph's Hospital and Senkatana center were invited to respond to a questionnaire, where socio-demographic data was gathered, including smoking history, occupation, method of cooking in their homes. The clinical characteristics that patients presented with were also recorded. Among patients who were aged 55 and above, 7 (6.5\%) patients had smoking history of more than 30 pack-years. These patients also had family history of lung disease and had worked in the mines or factory in the past. The 7 patients also presented with more than $90 \%$ of the clinical symptoms under investigation. Of these 7 patients; $2(6.3 \%)$ were found at Queen II, $1(4.2 \%)$ at St. Joseph while 4 (7.7\%) were found at Senkatana hospital. 48\% of the study participants were aged 55 and above, while $40 \%$ smoked for more than 30 years and $56 \%$ were male. $33 \%$ of the patients had a family history of lung disease, $21 \%$ had worked in mines or factories and $11 \%$ had been exposed to prolonged indoor air pollution. Studies show that the risk of lung cancer is 1.7 - fold higher in patients infected with Tuberculosis. It is therefore recommended that lung cancer screening with low dose computed tomography (LDCT) should be done on all Lesotho patients with active TB infection, who report to have smoked for more than 30 years and are aged greater or equal to 55 years.
\end{abstract}

Keywords: Lung Cancer, Tuberculosis, Computed Tomography Scan, Cross-Sectional Study

\section{Introduction}

Tuberculosis (TB) is a communicable disease, caused by the bacillus Mycobacterium tuberculosis. It is one of the major causes of ill health. [1] Studies have revealed that a quarter of the world population have been infected with TB and this constitutes approximately 1.7 billion individuals. [2] Worldwide reports show TB as one of the top 10 causes of death.[2, 3] A six-fold increase in tuberculosis prevalence in South Africa over the past two decades has been reported in South Africa in the year 2010. [4] This was attributed to the high prevalence of HIV/AIDS in that country. In their report for the period 2016 - 2020, the world health organization (WHO) has ranked the country of Lesotho among the top 30 high tuberculosis burden countries in the world. $[1,2,5]$ These 30 high TB burden countries account for almost $90 \%$ of those who fall sick with TB each year. Several reports show more TB cases among men than women. [2, 5]

Cancer accounted for nearly 10 million deaths in 2020 and thus remains the leading cause of death worldwide. $[2,6]$ There were 2.21 million cases of lung cancer in 2020, placing lung cancer incidence second only to breast cancer. However, lung cancer was reported the leading cause of cancer deaths in 
2020 accounting for 1.80 million deaths worldwide. [6] However, in Lesotho lung cancer cases constituted 5.1\% $(n=34)$ of all reported cancers in men $(n=670)$ during the year 2020. Lung cancer was ranked the $5^{\text {th }}$ among the top 5 cancers diagnosed in Lesotho men. The most prevalent cancers in men being prostate, Kaposi sarcoma, oesophagus, colorectum and lung cancer respectively. [7]

One main strategy to reduce the cancer burden is early detection of cancer and appropriate treatment and care of patients who develop cancer. [1, 2, 8] During chest imaging of patients who present with symptoms of lung disease, when new lesions are discovered, mycobacterium tuberculosis is usually highly suspected than malignancy, thereby delaying the diagnosis of lung cancer. [9] Lung cancers are therefore usually diagnosed at a more advanced stage of the disease leading to subsequent increased morbidity and mortality. [8] There is evidence of approximately $57 \%$ diagnosis of lung cancer at an advanced stage and 16\% early diagnosis. [9] In low resource countries like Lesotho, a lot of cases of lung cancer may be missed through a misdiagnosis of such cases as tuberculosis.

The clinical manifestations of tuberculosis infection are shared with pulmonary malignancy. [9-12] Therefore, there is a challenge for clinicians as lung cancer may be mistaken for pulmonary tuberculosis. [10] This diagnostic dilemma is one that will continue to plaque clinicians for many decades. [9] Several studies have shown that lung cancer may predispose patients to lung infection with tuberculosis. [11-13] In a systematic review of many studies performed the association of tuberculosis with lung adenocarcinoma was noted particularly in non-westernised countries. [14, 15] This study provided a compelling evidence of increased lung cancer risk among individuals with tuberculosis. The coexistence of lung cancer and pulmonary tuberculosis has been reported as a huge challenge for diagnosis and surgical treatment. [16] Furthermore, morbidity and death due to lung disease is increased when lung cancer is accompanied by an active pulmonary tuberculosis. [9, 16, 17]

The American Association of Thoracic Surgery has established patients to be at high risk of lung cancer if they are aged is 55 years or greater and have a smoked for more than 30 years. [9, 18] Furthermore, Active pulmonary tuberculosis infection has been shown to be a risk factor for lung cancer through prolonged pulmonary inflammation, scar formation and genetic alterations. [19] Tuberculosis is associated with a 1.7 - fold elevation in the risk of lung cancer. $[19,20]$ It is recommended that patients with active TB infection, greater or equal to 55 years of age with a smoking history of greater or equal to 30 pack years to be assessed with computed tomography (CT) for underlying malignancy prior to beginning tuberculosis treatment, even in the presence of a clinical or microbiologic diagnosis of tuberculosis. [21]

\section{Methods}

\subsection{Study Design}

A cross-sectional study was conducted among patients with active TB infection, undergoing therapy at Queen Elizabeth II hospital (Queen II), St. Joseph's hospital and Senkatana Center of Excellence clinic over a period of 2 months between April and May 2019.

\subsection{Setting}

Queen II is a hospital has been Lesotho's main secondary health care center until 2011 when it was replaced by Queen Mamohato Memorial Hospital (QMMH); a hospital build which has around 425 beds and has been constructed on a public-private partnership (PPP) basis. [22] In 2019, selected services including TB treatment were still provided at Queen II until its complete closure in 2020. This hospital was in the central business district (CBD) of the Maseru district, providing health care services to an estimated population of 220,000 .

St. Joseph's hospital also known as Roma hospital is a Roman Catholic privately-owned health facility situated in the Roma valley, located $37 \mathrm{~km}$ from Maseru, the capital city of Lesotho. It is one of the eighteen (18) hospitals forming the Lesotho Health Service System. It provides services to a large part of the lowlands, foothills and mountains of Maseru district.

Senkatana Center of Excellence is located at the Botshabelo complex in Maseru, and was established in 2004 to address the HIV/AIDS epidemic as the first public site to pilot antiretroviral therapy (ART) in Lesotho. This center is composed of several units including adult TB outpatient (OPD) department, a pediatric TB OPD department, a multi-drug resistant (MDR)-TB hospital and a leprosy hospital. [23] The current study was conducted in the adult TB OPD department and MDR-TB hospital.

\subsection{Study Population}

The study population comprised of all adult patients diagnosed with active pulmonary tuberculosis and undergoing antituberculosis therapy (ATT) at Queen II, St. Josephs and Senkatana center of excellence TB units. All adult patients with a diagnosis of tuberculosis and under ATT at the above healthcare centers were included in this study and patients under the age of 18 , or those without a confirmed diagnosis of tuberculosis and those who were too ill to respond to questions were excluded from the study. To select the study participants, convenience sampling was used and all patients who were present during the time when the study researchers were at these centers had an equal chance of being selected to participate in the study. The researchers explained the purpose of the study in Sesotho (the local language) to all patients who met the inclusion criteria. Written consent was then requested from all patients who were eligible and willing to participate in the study.

\subsection{Data Collection}

During the months of April and May, data was collected three times a week. A structured questionnaire was used to collect data. The data collection tool was adopted from the 'Weill Cornell Medicine Lung cancer screening program for 
high risk individuals' with modification to fit the Lesotho setting. Interviews were then conducted with all study participants and the researchers filled out the questionnaires. Socio-demographic data were obtained for each patient, their smoking history and clinical characteristics were obtained. All information obtained from the participants was cross-checked against the entries in the medical records. Researcher wore personal protective equipment (PPE) during the data collection to minimize their chances of contacting TB from the participants.

\subsection{Data Analysis}

Data was captured into microsoft excel. Data cleaning and internal validation was carried out to ensure that data was complete. Data analysis was performed using descriptive statistics; results summarised as count and percentages for qualitative variables and mean $(+\mathrm{SD})$ for quantitative variables. Independent variables were age, gender, occupation, clinical characteristics, tuberculosis infection, smoking history and family history of lung cancer. Outcome variable was lung cancer preliminary diagnosis.

\subsection{Definitions}

The following are the study definitions:

TB patients were defined as those individuals with a definite diagnosis of TB infection and undergoing ATT at Queen II, St. Joseph's or Senkatana center of excellence. Current smokers were those patients who reported to have been smoking prior to their admission into the hospital, or those who are currently smoking, or patients who report to have stopped smoking less than a year ago. A participant was reported to have familial history of lung disease if they reported any of their close relatives to have previously been diagnosed of tuberculosis and/or lung cancer. Occupations with high risk of lung cancer included those involved in mining and factory work. Patients with high risk of tuberculosis were defined as those with ages greater or equal to 55, with a diagnosis of tuberculosis and a smoking history of 30 pack years. A preliminary diagnosis of lung cancer was done in high risk individuals who had familial history of lung disease, worked in high risk job, presented with symptoms of superior vena cava syndrome (SVCS) like hoarseness when breathing, chest pain, hemoptysis and had poor ATT outcomes.

\subsection{Ethics}

Ethical approval for the study was obtained from the National University of Lesotho research and ethics board; institutional research board (IRB) as well as the ministry of Health.

Table 1. Socio-demographic characteristics of studied population.

\begin{tabular}{llll}
\hline & Queen II & St. Joseph & Senkatana \\
\hline Age groups, years & 2 & & 9 \\
$20-39$ & 15 & 4 & 19 \\
$40-55$ & 11 & 7 & 22 \\
$55-64$ & 4 & 12 & 2 \\
$\geq 65$ & 11 & 8 & 14 \\
Gender & 21 & 16 & 38 \\
Female & 22 & 18 & 25 \\
Male & 10 & 6 & 27 \\
Smoking habit & & 3 & 12 \\
Never smoker & 8 & 21 & 40 \\
Smoker & 24 & 1 & 7 \\
Occupation & 4 & 23 & 45 \\
Mine/Factory worker & 28 & 24 & 52 \\
Other & & 12 & 19 \\
Home cooking method & 32 & & \\
Firewood & 5 & & \\
Other & & & \\
Medical History & Active Pulmonary Tuberculosis & & \\
Family history of PTB & & & \\
\hline
\end{tabular}

\section{Results}

All patients who met the inclusion criteria and were invited to participate in the study gave consent and a total of 108 patients were enrolled; 32, 24 and 52 patients from Queen II, St. Joseph's and Senkatana health care centers respectively. Queen II had 15 (47\%), St. Joseph's 13 (54\%) and Senkatana $24(46 \%)$ patients aged 55 and above. This makes a study sample of $48 \%(n=52)$ aged 55 and above. Majority of participants were males with Queen II male population constituting $66 \%(n=21)$, there was $67 \%(n=16)$ males at St. Joseph's and 73\% $(n=38)$ males at Senkatana. As shown in Table 1, 31\% $(\mathrm{n}=10)$ reported to be smokers among Queen II participants while $25 \%(\mathrm{n}=6)$ smokers were in St. Joseph's and $52 \%(\mathrm{n}=27)$ at Senkatana. A total of 43 patients $(40 \%)$ of the study participants were smokers. A minority $(n=23,11 \%)$ reported to have either worked in the mines or factories. A total of 36 patients; $33 \%$ reported to have a family history of lung disease.

The most common clinical characteristics that patients presented with were backache $(94.8 \%)$, hoarseness when 
breathing (65.3\%), fever (47.5\%) and chest pain (45.8\%) with nail deformity being the least prevalent at $20.4 \%$, Table 2 .

Among patients who were aged 55 and above, 7 (6.5\%) patients had smoking history of more than 30 pack-years. These patients also had family history of lung disease and had worked in the mines or factory in the past. The 7 patients also presented with more than $90 \%$ of the clinical symptoms under investigation. Of these 7 patients; $2(6.3 \%)$ were found at Queen II, 1 (4.2\%) at St. Joseph while $4(7.7 \%)$ were found at Senkatana hospital.

Table 2. Clinical Manifestations suggestive of Tuberculosis and/or Lung Cancer.

\begin{tabular}{|c|c|c|c|}
\hline & Queen II (n, \%) & St. Joseph's (n, \%) & Senkatana $(n, \%)$ \\
\hline Fever & $3(9.4 \%)$ & $5(20.8 \%)$ & $9(17.3 \%)$ \\
\hline Rapid weight loss & $3(9.4 \%)$ & $1(4.2 \%)$ & $4(7.7 \%)$ \\
\hline Blood sputum & $5(15.6 \%)$ & $2(8.3 \%)$ & $3(5.8 \%)$ \\
\hline Respiratory failure (Hoarseness when breathing) & $10(31.3 \%)$ & $4(16.7 \%)$ & $9(17.3 \%)$ \\
\hline Chest pain & $4((12.5 \%)$ & $2(8.3 \%)$ & $13(25 \%)$ \\
\hline Nail deformity & $2(6.3 \%)$ & $2(8.3 \%)$ & $3(5.8 \%)$ \\
\hline Backache & $14(43.8 \%)$ & $9(37.5 \%)$ & $7(13.5 \%)$ \\
\hline
\end{tabular}

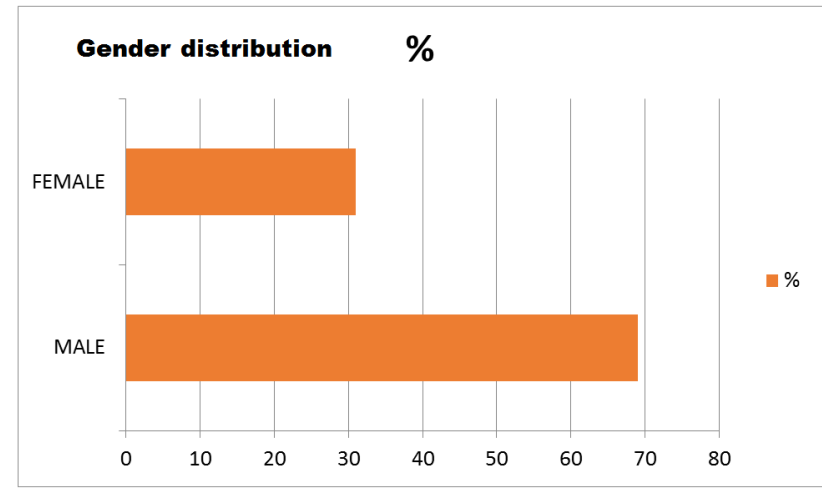

Figure 1. Gender distribution.

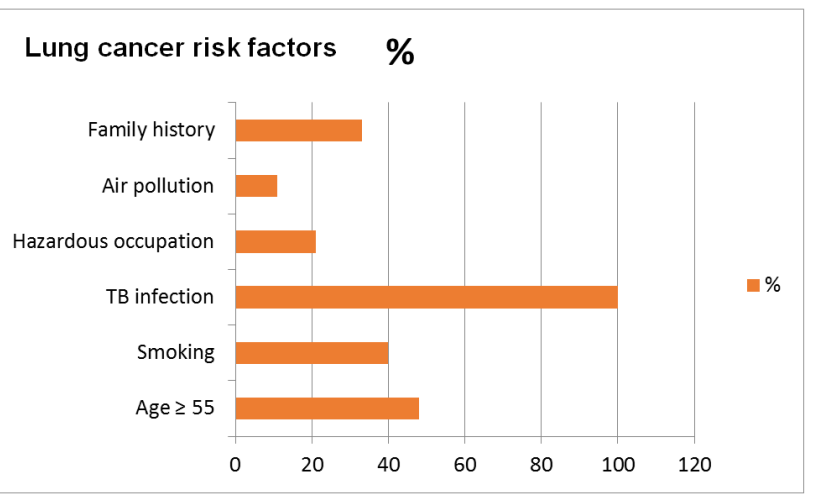

Figure 2. The prevalence of lung cancer risk factors among studied population.

\section{Discussion}

In this present study conducted among 108 adult TB patients at Queen II, St. Joseph and Senkatana, majority of respondents were male patients. TB has been reported to affect both sexes; however the highest burden $(56 \%)$ is in adult men. [1] The prevalence of smoking has also been reported higher in men than women and the causal association between and smoking and lung diseases including cancers is a long firmly established phenomena. [21, 24] This can account for the higher prevalence of lung diseases in men. However, $5-10 \%$ of lung cancers occur in women who have never smoked. [24] The presence of a lung disease further exposes non-smoking women to lung cancer. [27] In this current study 2 women were among the participants who were to be recommended for a low dose computed tomography (LDCT) screening for lung cancer because of their high risk lung malignancy. Studies have also shown no significant sex difference in the development of lung cancer in young age groups: both men and women have a $0.03 \%$ likelihood of developing lung cancer up to the age of $39 .[25,26]$

Among the study participants, $48 \%$ were aged 55 or above. Lung cancer incidence among patients diagnosed with TB is higher among elderly patients. [25]. Lung diseases including lung cancer has been shown to be a disease of older population. [25]

The study participants constituted $40 \%(n=43)$ of smokers. Several reports have shown that smoking is one of the main drivers of lung cancer; majority of patients who had tuberculosis and were screened for lung cancer using computed tomography had a lung cancer outcome. However, there are cases of lung cancer in non-smokers; these could be due to passive smoking, being in hazardous occupations where one is exposed to chemicals like radon or silica, using coal and firewood for cooking in a poorly ventilated kitchen. [10, 24, 27]

Furthermore, there is strong evidence that family history of lung cancer, especially if the relative was diagnosed at younger age, is one of the greatest risk factors for lung cancer development in an individual. [27, 31, 32] 36 patients (33\%) reported to have a first-degree relative who was diagnosed of a lung disease. Positive family history of any cancer has been shown to be associated with over 2-fold risk of developing lung cancer than negative family history. [28]

\section{Conclusion}

There is strong evidence that pulmonary tuberculosis infection is a risk factor for lung cancer. [29, 30] Therefore, it is imperative to refer patients who seem to not respond well to TB treatment for screening of lung cancer with LDCT. The presence of malignancy in lung infection has been associated with increased mortality. The fact that TB and lung cancer present with mutual symptoms poses a diagnostic challenge that clinicians could tackle by having equal suspicion for both diseases and investigate on both diseases before putting patients on any lengthy treatment. 
It is recommended that a case series of Lesotho patients with a confirmed diagnosis of both lung cancer and tuberculosis infection should be done.

\section{Conflicts of Interest}

The authors declare that they have no competing interests.

\section{References}

[1] Kyu HH, Maddison ER, Henry NJ, Mumford JE, Barber R, Shields C, Brown JC, Nguyen G, Carter A, Wolock TM, Wang $\mathrm{H}$. The global burden of tuberculosis: results from the Global Burden of Disease Study 2015. The Lancet Infectious Diseases. 2018 Mar 1; 18 (3): 261-84.

[2] WHO. Global Tuberculosis Report. 2020.

[3] Houben RM, Dodd PJ. The global burden of latent tuberculosis infection: a re-estimation using mathematical modelling. PLoS medicine. 2016 Oct 25; 13 (10): e1002152.

[4] Wood R, Liang H, Wu H, Middelkoop K, Oni T, Rangaka MX, Wilkinson RJ, Bekker LG, Lawn SD. Changing prevalence of tuberculosis infection with increasing age in high-burden townships in South Africa. The international journal of tuberculosis and lung disease. 2010 Apr 1; 14 (4): 406-12.

[5] Chakaya J, Khan M, Ntoumi F, Aklillu E, Fatima R, Mwaba P, Kapata N, Mfinanga S, Hasnain SE, Katoto PD, Bulabula AN. Global Tuberculosis Report 2020-Reflections on the Global TB burden, treatment and prevention efforts. International Journal of Infectious Diseases. 2021 Mar 11.

[6] Ferlay J, Colombet M, Soerjomataram I, Parkin DM, Piñeros M, Znaor A, Bray F. Cancer statistics for the year 2020: An overview. International Journal of Cancer. 2021 Apr 5.

[7] Sung H, Ferlay J, Siegel RL, Laversanne M, Soerjomataram I, Jemal A, Bray F. Global cancer statistics 2020: GLOBOCAN estimates of incidence and mortality worldwide for 36 cancers in 185 countries. CA: a cancer journal for clinicians. 2021 May; 71 (3): 209-49.

[8] Curry SJ, Byers T, Hewitt M. Potential of screening to reduce the burden of cancer. InFulfilling the Potential of Cancer Prevention and Early Detection 2003. National Academies Press (US).

[9] Parker CS, Siracuse CG, Litle VR. Identifying lung cancer in patients with active pulmonary tuberculosis. Journal of thoracic disease. 2018 Oct; 10 (Suppl 28): S3392.

[10] Wu CY, Hu HY, Pu CY, Huang N, Shen HC, Li CP, Chou YJ. Pulmonary tuberculosis increases the risk of lung cancer: a population-based cohort study. Cancer. 2011 Feb 1; 117 (3): 618-24.

[11] Engels EA, Shen M, Chapman RS, Pfeiffer RM, Yu YY, He X, Lan Q. Tuberculosis and subsequent risk of lung cancer in Xuanwei, China. International journal of cancer. 2009 Mar 1; 124 (5): 1183-7.

[12] Brenner AV, Wang Z, Kleinerman RA, Wang L, Zhang S, Metayer C, Chen K, Lei S, Cui H, Lubin JH. Previous pulmonary diseases and risk of lung cancer in Gansu Province, China. International journal of epidemiology. 2001 Feb 1; 30 (1): 118-24.
[13] Zheng W, Blot WJ, Liao ML, Wang ZX, Levin LI, Zhao JJ, Fraumeni JF, Gao YT. Lung cancer and prior tuberculosis infection in Shanghai. British journal of cancer. 1987 Dec; 56 (4): 501-4.

[14] Yu YH, Liao CC, Hsu WH, Chen HJ, Liao WC, Muo CH, Sung FC, Chen CY. Increased lung cancer risk among patients with pulmonary tuberculosis: a population cohort study. Journal of Thoracic Oncology. 2011 Jan 1; 6 (1): 32-7.

[15] Liang HY, Li XL, Yu XS, Guan P, Yin ZH, He QC, Zhou BS. Facts and fiction of the relationship between preexisting tuberculosis and lung cancer risk: a systematic review. International journal of cancer. 2009 Dec 15; 125 (12): 2936-44.

[16] Cicènas S, Vencevičius V. Lung cancer in patients with tuberculosis. World Journal of Surgical Oncology. 2007 Dec; 5 (1): $1-5$.

[17] Wang XR, Ignatius TS, Chiu YL, Qiu H, Fu Z, Goggins W, Au JS, Tse LA, Wong TW. Previous pulmonary disease and family cancer history increase the risk of lung cancer among Hong Kong women. Cancer Causes \& Control. 2009 Jul; 20 (5): 757-63.

[18] He XZ. A case-control study on risk factors of lung cancer. Lung Cancer. 1991; 7 (Suppl: 7).

[19] Dheda K, Booth H, Huggett JF, Johnson MA, Zumla A, Rook GA. Lung remodeling in pulmonary tuberculosis. The Journal of infectious diseases. 2005 Oct 1; 192 (7): 1201-10.

[20] Young RP, Hopkins RJ, Christmas T, Black PN, Metcalf P, Gamble GD. COPD prevalence is increased in lung cancer, independent of age, sex and smoking history. European Respiratory Journal. 2009 Aug 1; 34 (2): 380-6.

[21] Falagas ME, Kouranos VD, Athanassa Z, Kopterides P. Tuberculosis and malignancy. QJM: An International Journal of Medicine. $2010 \mathrm{Jul}$ 1; 103 (7): 461-87.

[22] Health systems in Lesotho". Commonwealth Health. Commonwealth Health. Retrieved 18 June 2021.

[23] https://www.pedaids.org/wp-content/uploads/2017/11/Lesotho Senkatana2015_2.pdf

[24] Lubin JH, Caporaso NE. Cigarette smoking and lung cancer: modeling total exposure and intensity. Cancer Epidemiology and Prevention Biomarkers. 2006 Mar 1; 15 (3): 517-23.

[25] Wu AH, Fontham ET, Reynolds P, Greenberg RS, Buffler P, Liff J, Boyd P, Henderson BE, Correa P. Previous lung disease and risk of lung cancer among lifetime nonsmoking women in the United States. American journal of epidemiology. 1995 Jun $1 ; 141$ (11): 1023-32.

[26] Venuta F, Diso D, Onorati I, Anile M, Mantovani S, Rendina EA. Lung cancer in elderly patients. Journal of thoracic disease. 2016 Nov; 8 (Suppl 11): S908.

[27] Thomas L, Doyle LA, Edelman MJ. Lung cancer in women: emerging differences in epidemiology, biology, and therapy. Chest. 2005 Jul 1; 128 (1): 370-81.

[28] Alavanja MC, Brownson RC, Boice Jr JD, Hock E. Preexisting lung disease and lung cancer among nonsmoking women. American journal of epidemiology. 1992 Sep 15; 136 (6): 623-32.

[29] Kanwal M, Ding XJ, Cao Y. Familial risk for lung cancer. Oncology letters. 2017 Feb 1; 13 (2): 535-42. 
[30] Nalbandian A, Yan BS, Pichugin A, Bronson RT, Kramnik I. Lung carcinogenesis induced by chronic tuberculosis infection: the experimental model and genetic control. Oncogene. 2009 Apr; 28 (17): 1928-38.

[31] Sooro MA, Zhang N, Zhang P. Targeting EGFR-mediated autophagy as a potential strategy for cancer therapy. International journal of cancer. 2018 Nov 1; 143 (9): 2116-25.

Islam M, Sooro MA, Zhang P. Autophagic regulation of p62 is critical for cancer therapy. International Journal of Molecular Sciences. 2018 May; 19 (5): 1405. 